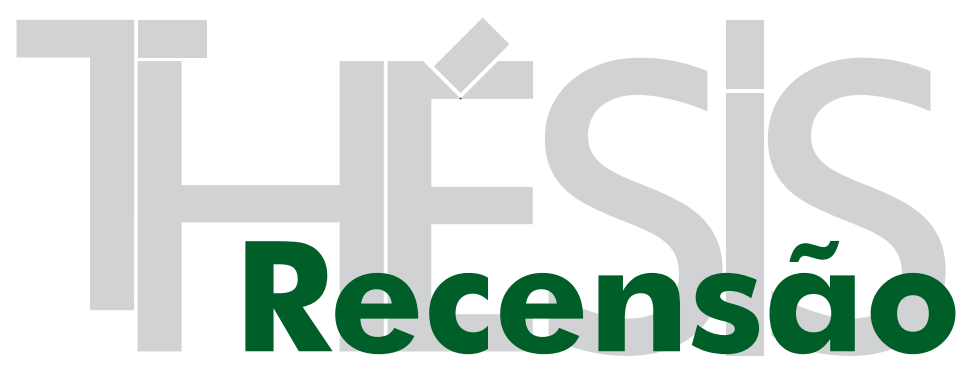




\title{
Diagramática, em vogais e consoantes consonantes e dissonantes
}

\author{
Luiz Amorim
}

Luiz Amorim é arquiteto e urbanista, formado pela Universidade Federal de Pernambuco em 1982, tendo concluído o PhD em Advanced Architectural Studies na Bartlett School of Graduate Studies - University College London, em 1999. É Professor Titular do Departamento de Arquitetura e Urbanismo da UFPE, docente do Programa de Pós-Graduação em Desenvolvimento Urbano (MDU), onde coordena o Laboratório de Estudos Avançados em Arquitetura (IA2) e o Grupo de Pesquisa de Morfologia da Arquitetura e do Urbanismo. Também é professor permanente do Programa de Pós-Graduação em Arquitetura e Urbanismo (PPGAU) da Universidade Federal da Paraíba (UFPB). É pesquisador 1B do ConseIho Nacional de Desenvolvimento Científico e Tecnológico (CNPq), onde foi membro titular do Comitê de Assessoramento de Arquitetura, Demografia, Geografia, Turismo e Planejamento Urbano e Regional (CA-SA), entre 2010 e 2013. É editor da Revista Thésis, membro do Space Syntax International Steering Committee e dos comitês editoriais das revistas Arquitextos, The Journal of Space Syntax (JOSS), Revista de Morfologia Urbana e da Editora FRBH.

1 A comissão avaliadora foi composta, além de nós coordenadores, dos professores Fernando Ruttkay Pereira (UFSC), Maria Cristina da Silva Leme (USP), Rachel Coutinho (UFRJ).

${ }^{2}$ Fizeram parte da comissão de parecerista os professores André Tavares (ETH - Zurich), Benamy Turkienicz (UFRGS), Cibele Rizeck (IAU), Claudia Amorim (UnB), Cristovão Duarte (UFRJ), Eugênio Queiroga (USP), Ester Gutierrez (UFPel), Frederico Holanda (UnB), José Belomont Pessôa (UFF), Laurente Vidal (Université de la Rochelle), Paulo Rheingantz (UFRJ), Vera Tangari (UFRJ).

3 ROWE, C. As I was saying (1989). Londres: MIT Press, 1996, p. 356, tradução nossa.
Por convite do professor Rodrigo de Faria, Presidente do Prêmio ANPARQ 2016, coordenamos, eu e a professora Ângela Gordilho, sua modalidade Tese. Satisfez-me, além do prazer de trocar ideias com os membros da comissão avaliadora ${ }^{1}$ e pareceristas ${ }^{2}$, a leitura de um belo e diverso conjunto de trabalhos científicos, cujas questões de investigação envolviam o fazer, o pensar, o capturar, o educar, o descrever, o analisar e o vivenciar o edifício e a cidade, não exatamente numa relação matricial de mútua associação, mas, de uma forma ou de outra, acompanhados por seus autores e pensamentos referentes, revelando a maturidade dos seus autores e o seguro acompanhamento dos seus orientadores. Um quadro amplo, mas limitado, é verdade, da sólida produção brasileira, da qual deverse-ia indicar uma excepcionalidade. Uma difícil tarefa para todos os envolvidos, salvo quando o primeiro parágrafo de uma das concorrentes se apresenta ao leitor da seguinte maneira:

Parto do princípio de que qualquer arquitetura é determinada por um mito que é amplamente aceito. Pode ser a noção de que a Antiguidade era melhor do que os dias atuais, que o futuro será melhor do que hoje, ou que o engenheiro é melhor do que o arquiteto.

Colin Rowe ${ }^{3}$ 
É possível que todas as teorias da arquitetura sejam mitos, e que a própria ideia de que existe algo chamado arquitetura seja uma invenção. Também é certo que na origem, a arquitetura não se desvencilha das suas muitas possibilidades, as que começam a ser desenhadas antes de função alguma, como formas, e que fora da narrativa que resguarda suas verdades, essas possibilidades são procuras desnecessárias. Na definição de arquitetura de Colin Rowe, o mito não é apenas uma licença poética, é o caminho para conhecer a ideia da teoria como arquitetura, na perspectiva de outro modo de escrita: a que dá sentido à necessidade e à ausência, a escrita das formas que o arquiteto inaugura com seus esquemas a priori, que são construções na linguagem. No espaço, a forma enfrenta a contingência, mas na linguagem ela margeia a necessidade, e não pode se moldar por ela, nem mesmo ao destino no qual o discurso a encerra. Em suas origens gregas, o conceito de forma aparece em duas perspectivas - a mitológica e a filosófica -, que esclarecem sobre a qualidade do trabalho do arquiteto Peter Eisenman. Forma vem do mito de Morfeus ${ }^{4}$, divindade da mitologia grega que habita uma caverna escura e que pode simular as fisionomias e as maneiras dos homens. Essa é uma concepção, a do trabalho de dar forma, a criação. A outra é oriunda da metafísica platônica. Para Platão, pensamos por meio de formas. Se pensamos, já são formas, que não são descrições fiéis das coisas, são aproximações. (IZAR, 2015, pp. 13-14)

Na precisão da escrita, como pode ser apreciada, estão consonantes todos os elementos estruturadores da investigação doutoral, desde a sublimação dos mitos, por Rowe; das conjecturas acerca da teoria como arquitetura; da forma e suas formas de escrita por meio de esquemas - diagramas; ao mito próprio que constitui a obra de Peter Eisenman. Nas subsequentes páginas Gabriela Izar, sua autora, cria, exemplarmente, uma narrativa que busca, por meio de uma leitura crítica da sua obra escrita e construída, demonstrar que a concepção e o uso de diagramas no desenvolvimento de projetos, arquitetônicos e teóricos, pois, indissociáveis, seriam a priori.

Toma, para o desenvolvimento do seu argumento, as casas experimentais de 1 a $11 \mathrm{~A}$, todas desenvolvidas entre os anos de 1966 e 1978, segundo o interesse do arquiteto de explorar a dissonância entre as propriedades da forma e os aspectos utilitários da arquitetura. Da primeira, busca, por meio de procedimentos geométricos (rotações, translações, intersecções, etc.), constituir uma diagramática geradora de arquiteturas. Da segunda, um pleno afastamento de teorias conhecidas, dos estilos já forjados, da recorrência de usos e ocupações do espaço arquitetônico. Observa, segundo um procedimento analítico centrado no ordenamento sequencial de geração dos diagramas e dos aspectos formais intrinsecamente a ele associados, o processo de desenvolvimento dos seus experimentos. Desenvolve um "sistema de referências" que possibi-
${ }^{4}$ No dicionário Bailly, a palavra forma provem de morphê e significa: 1) Forma, forma do corpo, figura, exterior. 2) forma, aparência. 3) forma, tipo, espécie. 4) forma artificial, gesticulação, semblante (aparência). Na mitologia, Morfeus (Morpheus) é aquele que reproduz as formas, Deus do sono e dos sonhos. (BAILLY). Na tradução espanhola das Metamorfoses (Ovidio), Morfeu é um artífice das formas: Mas el padre, del pueblo de sus mil hijos, despierta al artífice y simulador de figuras, (635) a Morfeo: no que él ninguno otro más diestramente reproduce el caminar y el porte y el sonido del hablar. Añade además los vestidos y las más usuales palabras de cada cual. Pero él solo a hombres imita. Ovidio, Metamorfosis, versão eletrônica disponível em: http://www.biblioteca. org.ar/libros/133611.pdf 
lita a leitura da casas experimentais ao longo do seu processo de concepção, observadas como se "fossem isomorfismos de uma cadeia topológica de propriedades diagramáticas que evoluem dentro do processo que Ihes dá forma, e que se tornam autônomas em relação ao contexto temporal no qual foram originalmente elaboradas" (IZAR, 2015: pp. 22). Portanto, permite compreender como Eisenman desenvolve sua investigação formal.

Se esta seção tem início com a clareza das suas palavras, devo encerrar com outras de sua lavra:

As análises revelaram algumas qualidades fundamentais do trabalho de Eisenman: as casas derivam da mesma base notacional e de procedimentos; na cronologia sugerida na numeração original dada por Eisenman, as formas das casas evoluem geometricamente segundo um princípio de expansão de um centro absoluto à periferia, do bloco único aos pavilhões; no curso da série, o trabalho diagramático vai se tornando mais complexo em termos das codificações e das parametrizações e, com isso, acarreta também em uma sistemática progressivamente mais complexa em termos de procedimentos e de referências geométricas; a qualidade da série é a de uma rede de formas e de significados agenciada pelo modo como Peter Eisenman emprega o diagrama, como um conceito que opera no tempo, não como um modelo para toda a série e para todas as casas. (IZAR, 2015, p. 23)

\section{B}

A tese é estruturada em nove capítulos, além de introdução e conclusão. A autora não o faz, mas poderia ser dividida em duas partes. A primeira seria dedicada à contextualizar, problematizar e fundamentar sua aproximação da questão da tese. A segunda, estaria diretamente ligada ao objeto de estudo - as casas 1 a 11A. Da primeira parte fazem parte os capítulos de um a seis, e da segunda, os de sete a nove.

O primeiro capítulo é dedicado ao diagrama, da etimologia da palavra, à introdução da expressão diagramatologia, por William Mitchell (MITCHELL, W., 1981, apud IZAR, 2012) e à demonstração da sua transversalidade - pois "o ato de diagramar sempre envolve mais de uma área do conhecimento" (IZAR, 2012: pp. 29). O segundo capítulo traça o percurso profissional de Eisenman e o terceiro, um recorte aprofundado deste, reflete sobre sua formação acadêmica, onde é introduzido à leitura formal por seu orientador de PhD na Universidade de Cambridge, Colin Rowe, por sua vez, aluno de Rudolf Wittkower, ambos formalistas - com a licença da palavra. Neste é estabelecida e discutida a fundamental contribuição de Rowe para a sua formação. 
O capítulo subsequente, o quarto, apresenta uma crítica ao olhar diagramático de Christopher Alexander, contemporâneo de Einsenman em Cambridge, comparando sua abordagem funcionalista ao teor essencialmente formal, do segundo. Já os capítulos cinco e seis tratam das ideias forjadas durante a sua tese de PhD sobre a obra de Giuseppe Terragni, da sua gênese - seus fundamentos, ao seu desenvolvimento - a leitura crítica da arquitetura do arquiteto moderno italiano.

O Capítulo 7 inaugura o que seria a segunda parte da tese, com a apresentação do seu objeto de estudo: As casas seriadas de Peter Eisenman - seu título e conteúdo. Neste, são descritas, uma a uma, segundo sua sequência numérica. É no Capítulo 8 que os experimentos diagramáticos relativos às casas são estudados, devidamente explorados, sua investigação formal é explicitada e é construída a ideia central do capítulo 9: a de que o arquiteto constrói, por meio de "diagramas que ordenam diagramas", uma rede não "hierarquizada porque estabelece conexões em várias direções" e, também, "porque opera com relações sintáticas que emergem, desaparecem, retornam e são transformadas, na interação do estudo de uma casa com o outro" (IZAR, 2015: pp. 281).

C

As qualidades que acabo de destacar, também foram enfatizadas nos pareceres emitidos pelos colegas com quem dividi a responsabilidade de apreciar as teses concorrentes do Pêmio Anparq 2016. Destaco algumas de suas partes como se a ecoarem minhas apreciações e a destacarem outros aspectos, mas também como forma de credita-los nesta resenha como coparticipes da tarefa conjunta que nos foi apresentada.

Ângela Gordilho começa por destacar, em seu parecer, como a tese "dialoga com os críticos e comentadores de Eisenman e como o próprio Eisenman [...] e o papel singular dos diagramas nos projetos de suas casas seriadas" e o faz pelo preenchimento das lacunas observadas pela autora. Ressalta, com grande ênfase, a qualidade da pesquisa documental, realizada no vasto acervo doado pelo arquiteto para o Canadian Center for Architecture (CCA), na cidade de Montreal, e The Getty Research Institute, parte do Getty Center, na cidade de Los Angeles.

Frederico de Holanda ressalta que ao investigar a forma na arquitetura, a autora coloca a tese "na boca de cena, e já isso, por si só, chama a atenção, mormente quan- 
do a norma no nosso campo (e isso vale para as outras teses no conjunto que me coube avaliar) é denegrir uma abordagem estritamente formal". E destaca que:

\begin{abstract}
A perspectiva teórica do trabalho também é clara e oportuna, posto que estética - a sua perspectiva - não tem recebido na reflexão crítica brasileira o status que mereceria. Destaca, ainda a pertinência da crítica do diagrama funcionalista de Alexander. [...] Enquanto a linguagem de padrões de Alexander visa criar um vocabulário de 'contingências', os diagramas de Eisenman visam transcender tempo e espaço. Faltou comentar quão normativa é a proposta de Alexander, quão precária é sua leitura da história, e quão insatisfatórias são suas classificações de cidades naturais e cidades artificiais (ainda que entendamos o contexto pós-funcionalista em que a dicotomia foi formulada).
\end{abstract}

E conclui que, por meio do seu estudo, "fica clara a especificidade de seu trabalho em arquitetura como linguagem autônoma. Esta é a chave de Eisenman, esta é a chave desta tese, o que implica um gratificante sopro de renovação na teoria crítica da arquitetura no Brasil." Aspecto que também é observado por Paulo Afonso Rheingantz em seu parecer final: "Trabalho denso, muito bem estruturado e apresentado, ricamente documentado e ilustrado, retrata com acuidade e profundidade a contribuição de um dos mais importantes produtores e pensadores da arquitetura contemporânea [...]"

\title{
D
}

A tese nos brinda, como visto, além das suas qualidades intrínsecas, com a perspectiva de expandir, por inteligente provocação temática, novos estudos no seio da comunidade científica e profissional interessada no projeto como objeto específico de investigação e, mais ainda, como investigação, per se. As casas experimentais de Eisenman encaixam-se exatamente neste limiar entre os clássicos procedimentos de investigação científica associados ao nosso campo em sua diversidade inerente, e o desenvolvimento de soluções objetivas para a resolução de um problema arquitetônico. É, de fato, uma investigação por projeto e não uma investigação sobre o projeto ou sobre métodos que dão suporte ao projeto. Evidentemente está associada ao projeto - objeto que contém informações que dão suporte à realização de determinado objeto habitável, e aos meios de constitui-lo, sejam eles de natureza puramente processual ou relacionado aos fundamentos teóricos aos quais estão associados.

Programas doutorais, como os oferecidos por instituições britânicas, como a Bartlett School of Architecture, Architecture Association School of Architecture e Edinburgh School of Art, vêm enfrentando o desafio de to- 
mar os processos e procedimentos de projeto como, forma, meio e objeto de investigação. Tomam-no como parte do conhecimento específico do campo da arquitetura, mas segundo perspectiva multidisciplinar, interdisciplinar e, em alguns casos, transdisciplinar. Em tais ambientes, digamos acadêmicos - expressão que evito, tendo em vista sua acepção corrente associada ao sentido de conservadorismo, o ato de projetar também é meio de investigação. A diagramática exposta por Gabriela Izar também o é.

Contamos, todos os interessados em ampliar as bases, os meios e os objetos de investigação em arquitetura, com esta belíssima literatura para estimular nossa reflexão sobre o assunto.

E

Finalmente, o documento que tenho em mãos - uso a expressão metaforicamente, pois não o tenho como objeto concreto, mas sim como objeto digital, deve ser publicado, no sentido próprio da palavra: tornado público. Ajudará a preencher uma lacuna na nossa literatura, como já destacado, e será, em particular, do interesse específico por parte dos investigadores que conseguem distinguir os campos específicos da teoria e da história da arquitetura.

Diagramática é uma demonstração clara de que a rede de programas de pós-graduação em arquitetura e urbanismo, após ter passado por as etapas de implantação, expansão e consolidação, têm se colocado, com o suporte das diversas agências nacionais de fomento à pesquisa, na fronteira da investigação científica internacional. E o Prêmio Anparq, em suas diversas categorias, a vem reconhecendo e divulgando, particularmente por meio deste seu periódico - a revista Thésis.

Espero que este sistema de formação de pesquisadores e de produção do conhecimento, da maneira como o conhecemos e como o ajudamos a atingir tal patamar de qualidade, se mantenha íntegro e se fortaleça nos tempos que se avizinham. Gabriela Izar é um dos seus gratos rebentos. Queremos ter o prazer de conhecer suas futuras produções, desenvolvidas, quiçá, com o suporte das instituições públicas de fomento à pesquisa e, certamente, com a contribuição da nossa comunidade acadêmica, cuja devoção ao conhecimento permanecerá e a ANPARQ, em seu conjunto de atribuições, continuará a cumprir o seu papel de colocar a nossa produção e o contexto em que está inserida em permanente escrutínio. 